stated one would also be sent by Spain : the duplication of stations is not desirable in such a case. The President's propositions were adopted, but in addition the Committee on Methods was also charged with the consideration of the calculations and publication of the observations in 1882 , and were further deputed to consider the formation of a temporary international bureau, to be intrusted with the reduction of the whole of the observations. At the fifth and last sitting of the Conference on October 13, the report from the Committee on Methods of Observation, \&c., was presented. The proposals of the British Commission respecting the phenomena to be noted at the contacts of the limbs of the sun and Venus, brought forward by Mr. Stone, were made the foundation for a series of instructions to observers, some explanations being appended thereto. After much divergence of opinion with regard to the advantage of an international bureau des calculs, the following proposition introduced by M. Dumas, and supported by Mr. Stone on the part of the English commission, was adopted by a large majority.

"The Conference expresses the wish that the French Government may be willing to communicate in diplomatic form with the other governments represented in this conference, or those who are interested in the transits of Venus, in order to lay before them the proposition of convoking, after the return of the expeditions of 1882 , an international conference on the transits of Venus, with a view to establish an understanding on the means to be adopted to arrive at the best and most expeditious use of the observations of the transits of 1874 and 1882 , and in particular to inquire whether towards this end a temporary international bureau should not be formed."

The report closes with a list of the projected stations for the expeditions, so far as at present arrarged. The British stations selected are:-Bermurla, Jamaica, Barbados, Cape Colony (3), Madagascar, New Zealand, Falkland Islands (?), with the Australian observatories.

\section{ON THE PHYSICAL CAUSE OF THE OCEAN}

\section{BASINS}

EOLOGISTS have reason to thank Prof. Ball for directing their attention to the remarkable investigations of Mr. G. H. Darwin upon "The Precession of a Viscous Spheroid, and the Remote History of the Earth," (Phil. Trans. Roy. Soc., Part ii., I879). Prof. Hull has already been led to point out one result which appeared to him to flow from them, in showing how the ancient tides may have produced the planes of marine denudation, though Mr. Darwin has since expressed doubts as to the legitimacy of this conclusion. I wish to offer another speculation arising from Mr. Darwin's work, which I think may account for the hitherto unexplained distribution of land and water upon the surface of the globe.

Herschel remarked long ago, in his "Physical Geography," that the prevalence of land and water over two opposite hemispheres "proves that the force by which the continents are sustained is one of tumefaction, inasmuch as it indicates a situation of the centre of gravity of the total mass of the earth somewhat eccentric relatively to that of the general figure of the external surface - the eccentricity lying in the direction of our antipodes : and is therefore a proof of the comparative lightness of the materials of the terrestrial hemisphere." In my "Physics of the Earth's Crust," just published, I have shown reasons for thinking that the distribution of the materials of the earth, which gives rise to this condition, is of the following kind. I accept on the whole the theory that the earth is a hot globe, of which the superficial crust is rendered solid by having become cool, and that the central part is solid, either from great pressure, or from whatever other cause may be assigned ; an intervening layer beneath the cooled crust still remaining liquid. The layers of which the whole is composed are arranged in order of their density. Now I have given reasons for believing that Herschel's "comparative lightness of the materials of the terrestrial hemisphere" arises from the fact that the cooled crust beneath the continents is intrinsically less dense than that beneath the great oceans. I think that the crust beneath the continents consists of the cooled acid, or granitic, and therefore lighter magma, which ought naturally to have formed originally the entire superficial portion of the globe. But I conclude that the bottoms of the great oceans consist nevertheless of a crust formed out of the cooled basic layer. Beneath the cooled crust the laws of hydrostatic equilibrium would require that, if the substratum is truly liquid, it should be of the same density under both these areas. I also conclude that the upper surface of the basic crust which forms the floor of the oceans is really depressed below the mean surface of figure.

To these conclusions I arrived without being able to suggest any satisfactory explanation of the facts. I saw that they agreed with, and were supported by, the view of those geologists who assert that the great oceanic and continental areas have never changed places; but neither could I any better see the reason for this.

Let us now inquire whether Mr. Darwin's researches throw any light upon the subject. I shall refer chiefly to the summary and discussion of results appended to his paper, for it is small blame to a sexagenarian, not a professed mathematician, to admit that to follow the calculations is beyond the scope of his powers. As I understand Mr. Darwin, he thinks it probable that the moon and the earth were once a single mass, and that at the time when this mass was rotating at the rate of about one revolution in five hours the whole separated into two portions, the smaller of which went to form the moon; and that the moon then began to recede from the earth, until now, after the lapse of fifty-four millions of years or more, it is at its present distance. The ellipticity of the mass when rotating at the above-named speed would be about I-I 2 th. [This would make the mass very much less compressed than an ordinary orange.] He does not think it probable that this amount of ellipticity would cause the spheroid to break up simply from the centrifugal effect of the rotation; but he suggests, judging from the calculated period of a gravitational oscillation of a fluid spheroid, of uniform density equal to the mean of the earth, viz. I hour 34 minutes, that the period of the free oscillation of a spheroid "consisting of a denser nucleus and a rarer surface," but of the same mean density as the earth, might coincide with the period of the bodily solar tide at that time. "It seems to be quite possible that two complete gravitational oscillations of the earth in its primitive state might occupy four or five hours." "Accordingly the solar tides would be of enormous height." He then adds : "Does it not then seem possible that, if the rotation were fast enough to bring the spheroid into anything near the unstable condition, then the large solar tides might rupture the body into two or more parts? In this case one would conjecture that it would not be a ring that would detach itself."

I now proceed to build my speculation upon his. It is obvious that, according to the above theory, the act of fissiparturition by which the moon was born must have been sudden. One of the two solar tidal protuberances broke away from the earth to inchoate a separate existence. A great but shallow hole must consequently have been formed, whose centre would have been on or near the equator. Prof. Ball says : "Not for long would that fragment retain an irregular form; the mutual attraction of the particles would draw the mass together. By the same gentle ministrations the wound on the earth would soon be healed. In the lapse of time the earth would become as whole as ever, and at last it would not retain even a scar to testify to the mighty catastrophe." 
I form a less hopeful prognostication. I think the ocean basins are the scar, which still testify to the place of separation.

The density of the moon is 0.56654 times that of the earth. Putting the mean density of the earth at 5.5 , this makes the density of the moon 3.I. The density of granite is about 2.68 , and that of basalt 2.96 . Consequently the density of the moon is a little greater than that of the basic layer of the earth's surface, which I think we may expect to occur at the sea-board at a depth of about 25 miles. The entire mass of the moon is 0.011364 of the mass of the earth.

Accordingly, it would require a layer of about $3 \mathrm{I}$ miles thick, of the density of granite, to be taken off the surface of the primitive mass to make a body of the mass of the moon; and if the mean density of the matter removed was the same as that of the moon, a somewhat thinner layer would suffice. But if we reduce the area of the skin removed to the area of the oceans, it would require to be $\frac{197}{146} \times 31$, or about $4 \mathrm{I}$ miles deep. Hence a uniform layer rather less than $4 \mathrm{I}$ miles thick taken off the oceanic areas would be sufficient to make the moon.

Of course the layer removed would not, in fact, have been of uniform thickness. But the above estimate gives an idea of the size of the cavity which would be produced. What then would happen? This would depend upon whether the surface had already become at all solid. I conceive this would be the case at a very early stage, judging from the manner in which a solid layer forms on the liquid lava of Kilauea. The hole would therefore fill up by the rise of the liquid from below, rather than by the lateral approach of the edges of the wound. When the raw surface again solidified we should have a crust of greater density over the area in question, because formed from a lower and denser layer, which would have risen not quite to the level of the lighter crust. There would, however, have necessarily been a certain amount of flow in the upper fluid layers towards the cavity, and this would have carried the cooled granitic crust which, floating on it, still remained upon the earth along with it. What was left of the granitic crust would therefore be broken up into fragmentary areas, now represented by the continents. This would make the Atlantic a great rent, and explain the rude parallelism which exists between the contours of America and the old World.

The sudden rupture of so considerable a fragment from the rotating spheroid, would alter its mass, form, and moment of momentum. It appears then that its axis of rotation would be altered, which might account for the fact, that the approximate pole of the oceanic area is not in the equator.

The volcanic surface of the moon, if volcanic it be, would lend considerable support to the view which I maintain, that the water substance emitted by volcanoes is an integral constituent of the fluid substratum. For when the moon broke away from the earth it would carry with it the aqueous constituent of the magma. Owing to the much smaller force of gravity in the moon, the pressure under which this would there be placed would be much less than in the earth. Consequently it would more easily escape, and the signs of volcanic action would be more pronounced. But the difficulties surrounding terrestrial vulcanism are so great, that one is hardly tempted to add the lunar to them. O. FISHER

\section{CLASSIFICATION OF THE DINOSAURIA ${ }^{1}$}

$\mathrm{IN}$ the May number of the American Journal of Science (p. 423) I presented an outline of a classification of the Jurassic Dinosaurian reptiles of this country

$x$ By Prof. O. C. Marsh. Read before the National Academy of Sciences, at the Philadelphia meeting, November 14,1881 . Communicated by the Author. which I had personally examined. The series then investigated is deposited in the Museum of Yale College, and consists of several hundred individuals, many of them well preserved, and representing numerous genera and species. To ascertain how far the classification proposed would apply to the material gathered from wider fields, I have since examined various Dinosaurian remains from other formations of this country, and likewise during the past summer have visited most of the museums of Europe that contain important specimens of this group. Although the investigation is not yet completed, I have thought the results already attained of sufficient interest to present to the Academy at this time.

In previous classifications, which were based upon very limited material conpared with what is now available, the Dinosaurs were very generally regarded as an order. Various characters were assigned to the group by von Meyer, who applied to it the term Pachypoda; by Owen, who subsequently gave the name Dinosauria, now in general use ; and also by Huxley, who more recently proposed the name Ornithoscelida, and who first appreciated the great importance of the group, and the close relation it bears to birds. The researches of Leidy and Cope in this country, and Hulke, Seeley, and others in Europe, have likewise added much to our knowledge of the subject.

An examination of any considerable portion of the Dinosaurian remains now known will make it evident to any one familiar with reptiles, recent or extinct, that this group should be regarded not as an order but as a subclass, and this rank is given it in the present communication. The great number of subordinate divisions in the group, and the remarkable diversity among those already discovered indicate that many new forms will yet be found. Even among those now known, there is a much greater difference in size and in osseous structure than in any other sub-class of vertebrates, with the single exception of the placental Mammals. Compared with the Marsupials, living and extinct, the Dinosauria show an equal diversity of structure, and variations in size from by far the largest land animals known-fifty or sixty feet long, down to some of the smallest, a few inches only in length.

According to present evidence the Dinosaurs were con fined entirely to the Mesozoic age. They were abundant in the Triassic, culminated in the Jurassic, and continued in diminishing numbers to the end of the Cretaceous period, when they became extinct. The great variety of forms that flourished in the Triassic render it more than probable that some members of the group existed in the Permian period, and their remains may be brought to light at any time.

The Triassic Dinosaurs, although so very numerous, are known to-day mainly from footprints and fragmentary osseous remains. Not more than half-a-dozen skeletons, at all complete, have been secured trom deposits of this period; hence, many of the remains described cannot at present be referred to their appropriate divisions in the group.

From the Jurassic period, however, during which Dinosaurian reptiles reached their zenith in size and numbers, representatives of no less than four well-marked orders are now so well known that different families and genera can be very accurately determined, and almost the entire osseous structure of typical examples, at least, be made out with certainty. The main difficulty at present with the Jurassic Dinosaurs is in ascertaining the affinities of the diminutive forms which appear to approach birds so closely. These forms were not rare, but their remains hitherto found are mostly fragmentary, and can with difficulty be distinguished from those of birds, which occur in the same beds. Future discoveries will, without doubt, throw much light upon this point.

Comparatively little is yet known of Cretaceous Dino- 